\title{
Análisis visual de la obra Creación de las aves de Remedios Varo
}

\author{
Visual analysis of "Creación de las aves" painting by \\ Remedios Varo
}

OSCAR GONZÁLEZ CARRARO*

Escuela Nacional de Estudios Superiores

México

*glz.carraro.oscar@gmail.com

(iD) https://orcid.org/0000-0002-9120-1347

Artículo de investigación

Recepción: 01 de Septiembre de 2020

Aprobación: 08 de Octubre de 2020

\section{Cómo citar este artículo:}

González Carraro, O. (2021). Análisis visual de la obra Creación de las aves de Remedios Varo. Designio. Investigación en diseño gráfico y estudios de la imagen, 3(1), pp. 68-89. Recuperado a partir de: http://cipres.sanmateo.edu.co/index.php/designio 


\section{Resumen}

La comprensión de una obra artística puede ser entendida como la asimilación de un continuo diálogo entre dos (2) temporalidades: la que posee por sí misma la obra, frente a la temporalidad del espectador que la observa. Este proceso de asimilación define el significado de una representación artística en un momento determinado de la historia. Bajo este principio se presenta a continuación el análisis visual de la obra Creación de las aves (1957), realizada por la artista Remedios Varo. El ejercicio centra su interés por definir diversos niveles de significación de la obra, a través de la propuesta de Erwin Panofsky y Didi-Huberman, de quienes se retoma el valor del anacronismo histórico como modelo de comprensión de una imagen detenida en el tiempo.

Palabras clave: iconología; dialéctica histórica; surrealismo; arte mexicano; análisis visual.

\section{Abstract}

An artistic work comprehension can be understood as the assimilation of a continuous dialogue between two (2) temporalities: that which the work possesses itself, as opposed to the temporality of the viewer who observes it. This assimilation process defines the meaning of an artistic representation at a given moment in history. Under this principle, the visual analysis of "Creación de las aves" (1957) work, by the artist Remedios Varo, is presented below. The exercise focuses his interest in defining various levels of significance of the work, through the Erwin Panofsky and Didi-Huberman proposal, from whom the value of historical anachronism, as a model for understanding an image stopped in time, is retaken.

Keywords: iconology; historical dialectic; surrealism; Mexican art; visual analysis. 


\section{0}

\section{Introducción}

La consolidación histórica del arte, en gran medida, depende de diversos factores sociopolíticos, así como económicos, que enmarcan el contexto en el cual se desarrollan las actividades de los artistas. Como ejemplo se ubica lo acontecido durante el conflicto bélico en España, a causa de la Guerra Civil en el año de 1940. Este hecho dio como resultado la llegada a México de refugiados, entre quienes arribaron pensadores, intelectuales y artistas, que brindaron al país una característica identidad manifiesta a través de las artes.

Del otro lado del Atlántico, el siglo XX en México atestiguó una etapa de constante dinamismo e importantes movimientos socioculturales entre los que destacan, en el ámbito de la plástica, la escuela muralista. Este movimiento, conformado por artistas como Diego Rivera, David Alfaro Siqueiros, J. Clemente Orozco, entre otros, cubría diversas estancias del país por medio de su didáctico propósito de conformación identitaria en la nación. A pesar de esta gran labor e influencia en las artes, también fueron los artistas exiliados; importantes exponentes de las vanguardias europeas, quienes lograron consolidar su presencia en el mundo del arte mexicano.

Este hecho es evidente a través del trabajo de la artista Remedios Varo, quien ajena a las manifestaciones de la escuela nacionalista llegó a México en busca de un ambiente apacible para desarrollar su producción pictórica, después de un inesperado exilio. De esta forma, interesado en la comprensión del desarrollo plástico de la artista española en México, el presente artículo retoma la obra Creación de las aves (1957) para llevar a cabo el estudio y comprensión de la pieza, por medio de distintos elementos.

El análisis visual desarrollado en las siguientes líneas sustenta su estructura, guiado por el método de interpretación de las imágenes expuesto por Erwin Panofsky, a través de la progresiva comprensión de la obra por medio de un acercamiento (pre)iconográfico e iconológico. A su vez, con la intención de renovar el acercamiento hacia la obra de arte, se retoma el planteamiento teórico de Didi-Huberman, por medio del modelo de anacronismo histórico, sustentado en la noción de dialéctica histórica propuesta por Walter Benjamin.

De esta forma, en un primer momento se dan a conocer datos biográficos y contextuales de la artista, mismos que fundamentan los principios esenciales que caracterizaron su desarrollo plástico. Posteriormente, se presentan los aspectos 
técnicos y formales de la obra Creación de las aves, acompañado de una propuesta de lectura para describir y transitar visualmente la pintura.

De forma consecutiva, se exponen los rasgos iconológicos de la obra para los cuales son recuperadas las interpretaciones previas llevadas a cabo por especialistas como Mircea Eliade, Janet A. Kaplan y Tere Arcq, quienes brindan elementos clave para dirigir la mirada a los sutiles e interesantes mundos en los que se adentró la artista para concebir su obra.

Estas interpretaciones son fortalecidas por el estudio de los símbolos que ofrecen teóricos como Jean Chevalier y Eduardo Cirlot, quienes fundamentan en gran medida la significación iconológica en la pintura. Sin dejar de lado el reconocimiento de la noción de montaje que propone Didi-Huberman a través del modelo diacrónico de la historia, aplicado a la interpretación iconológica. Finalizando con una serie de comentarios a manera de cierre, que exponen el estado de significación y recepción de la pieza en el momento actual, así como el valor y trascendencia del enfoque empleado para el presente texto.

\section{Vida, contexto y destino de Remedios Varo (1908-1963)}

Bautizada con el nombre de María de los Remedios Alicia Rodriga Varo y Uranga, mejor conocida como Remedios Varo, representa en nuestros días una de las figuras más importantes del movimiento surrealista en México. Nacida en Anglés, pequeño poblado al norte de Barcelona, el 16 de diciembre de 1908, fue instruida durante la infancia, por su padre Rodrigo Varo y Cejalvo, ingeniero especializado en obras hidráulicas, el cual, en palabras de Kaplan, fue:

Una persona que desempeñó un papel fundamental en la vida de Remedios. Tenía una imaginación que estimulaba la de su hija y le fomentó su formación artística, llevándola a museos y enseñándole el arte del dibujo técnico (...) la ejercitó en los rigores de su oficio, enseñándole el uso correcto de la regla, de la escuadra y del cartabón (...) Varo se quejaría más tarde de su actitud dominante, pero lo que aprendió bajo su tutela lo utilizaría a lo largo de toda su vida. (Kaplan, 2001, p. 15)

Aunado a lo anterior, su formación académica se vio complementada con la lectura de autores como: Alejandro Dumas, Julio Verne, Edgar Allan Poe, así como 
literatura de carácter místico y filosofía oriental. Interés particular que debió mantener oculto al recibir una educación religiosa en Madrid, hasta cumplidos los 16 años, edad en la cual, al reconocer su padre en ella la gran habilidad y gusto por el dibujo, fue inscrita dentro de la Real Academia de Bellas Artes de San Fernando.

La situación dentro de esta institución definió en gran medida la formación técnica de Remedios Varo, conducida por la labor de académicos que buscaban mantener el buen ejercicio y práctica artística. Además, vinculada a cánones y criterios de representación preestablecidos por artistas como Goya o Velázquez. Al respecto, el trabajo de Rosa María Recio, dirigido a comprender la situación cultural y formativa de artistas en la Academia de San Fernando a principios del siglo XX, brinda un panorama general a partir del estudio de diversos discursos de recepción, emitidos por académicos que ingresaban a dicha institución.

Por medio de este acercamiento es posible entender que la Real Academia de San Fernando, aun con las diversas manifestaciones parisinas de esbozos impresionistas, durante los primeros años del siglo XX fue concebida y dirigida como un "puente de la ortodoxia necesario por donde no se interrumpe el camino cuando surgen insospechadas simas" (Aguado, 2018, p. 159), es decir, movimientos vanguardistas.

Lo anterior no evitó que los estudiantes de la academia fueran conscientes y participes de dichas novedosas manifestaciones. No obstante, la educación académica buscó brindar a los futuros creadores las bases rigurosas de la formación artística. Inmersa en este contexto, Remedios Varo logró adquirir los saberes fundamentales para el desarrollo de su obra, en la Academia de San Fernando; son notorios en el estudio minucioso de bocetos preparatorios para cada una de sus piezas.

Como consecuencia y contacto con la diversidad de vanguardias latentes, paulatinamente el movimiento surrealista logró captar la atención de la artista durante sus años como estudiante de la academia. De esta manera, al concluir sus estudios en el año 1930, Varo se adhiere a la nueva corriente artística, al emprender el viaje a París, alejada de la situación política y bélica que estaba a punto de vivir España seis (6) años más tarde, por medio de la Guerra Civil.

Durante el año que duró la estancia de Remedios en París, llevó a cabo una serie de visitas y encuentros con personajes representativos del movimiento surrealista; definido por Bretón como un "automatismo psíquico puro por cuyo medio se intenta expresar tanto verbalmente como por escrito o de cualquier otro modo el funcionamiento real del pensamiento" (Bretón, 1924, p. 44). 
Ante este grupo, "Remedios asistía a sus reuniones, siempre con una actitud tímida, pero con una gran disposición de aprender de dicho ambiente cultural" (Tibol, 1957, p. 6). Dentro de estas reuniones la artista comenzó a realizar una serie de ejercicios artísticos, de carácter lúdico denominados cadáveres exquisitos ${ }^{1}$, los cuales dejaban ver un notorio acercamiento y construcción del estilo surrealista. Estos ejercicios continuaron desarrollándose por la joven al llegar a Barcelona, lugar en donde se radicó hasta 1936, debido a la tensión bélica y el riesgo de ser víctima de una rebelión que no eximiría a ninguna persona.

Por tanto, en 1937 Remedios Varo toma la decisión de viajar junto a Benjamin Péret $^{2}$, sin pensar que esa decisión traería como resultado la imposibilidad de retornar a su país de origen, al concluir dos (2) años más tarde la Guerra Civil. Como resultado, en 1941 Franco cierra las fronteras españolas a todo aquel que hubiese tenido relación alguna con la República (Kaplan, 2001, p. 53).

Aunado a lo anterior, y como consecuencia del inicio de la Segunda Guerra Mundial, la situación de inestabilidad social en París obligó a un gran número de intelectuales a buscar alternativas para emigrar a países alejados del conflicto bélico, donde comenzaban a darse grandes atentados de guerra y arrestos a campos de concentración. De este modo, imposibilitada de regresar junto a su familia, Remedios Varo logró salir a México junto a Péret, gracias al apoyo a refugiados por el conflicto bélico, durante el mandato del presidente Lázaro Cárdenas, para establecerse en el centro de la ciudad en 1941. Entonces, México fue el lugar que le brindó total seguridad, tal como lo manifestó la artista al decir:

Soy más de México que de ninguna otra parte. Conozco muy poco de España: era yo muy joven cuando viví en ella. Luego vinieron los años de aprendizaje de asimilación en París, después la guerra... Es en México donde me he sentido acogida y segura. (Varo, 1997, p. 14)

Aun cuando la situación en México mostraba constante rechazo a la población exiliada, la comunidad recién llegada logró consolidar un espacio en el cual compartían intereses y aficiones artísticas. Por ejemplo, en este espacio Remedios consolidó una entrañable amistad con la artista Leonora Carrington (de origen inglés).

\footnotetext{
${ }^{1}$ Composiciones colectivas al estilo collage, de imágenes obtenidas por medio de recortes de revistas antiguas, en las que participaban activamente diversos artistas en el siglo XX.

2 Poeta surrealista y militante revolucionario. Permitió ingresar a Remedios Varo al grupo surrealista en París y adherirse a los principios manifestados en su propia creación plástica.
} 
Junto a Carrington, Remedios Varo desarrolló cierta afición y deseo por comprender las leyes del ocultismo y alquimia, a través de la cocina, realizando diversas recetas y algunos métodos en los que jugaban y ponían sobre la mesa los artilugios de su imaginación (Bogzaran, 2008). Aunado a ello, la lectura y comprensión de textos de diversos autores como Blatvasky y Gurdjief (Madrid, 2013); los autores mostraban gran manejo de saberes acerca del ocultismo y la verdad absoluta, en relación con el autoconocimiento.

Dichas prácticas mantuvieron activa la creación e imaginario de Remedios Varo, siendo esta época en la cual se evidencia parte de su gran trabajo y obra madura, sin dejar de lado el gran impacto que tendría la última pareja de la artista, al referirnos con ello a Walter Gruen. Este hombre era un refugiado de origen austriaco quien, atraído por la figura de Varo, brindó una estabilidad para que la artista pudiera trabajar de manera continua, sin ninguna otra labor más que la creación plástica, la lectura y contemplación.

Es así que, llegado el año de 1957 Remedios Varo dedica su tiempo y actividad intelectual a realizar el boceto de la pieza Creación de las aves, la cual refleja no sólo su sólida formación académica, mostrada a través del firme diseño en trazos y objetos previamente estudiados; además, sus aspiraciones y filosofía condensadas en la continua creación de seres y mundos con una clara visión de trascendencia y autoconocimiento personal. Sin embargo, interrumpido a causa de un infarto al miocardio un ocho (8) de octubre de 1963. 
Figura 1. Creación de las aves (1957)

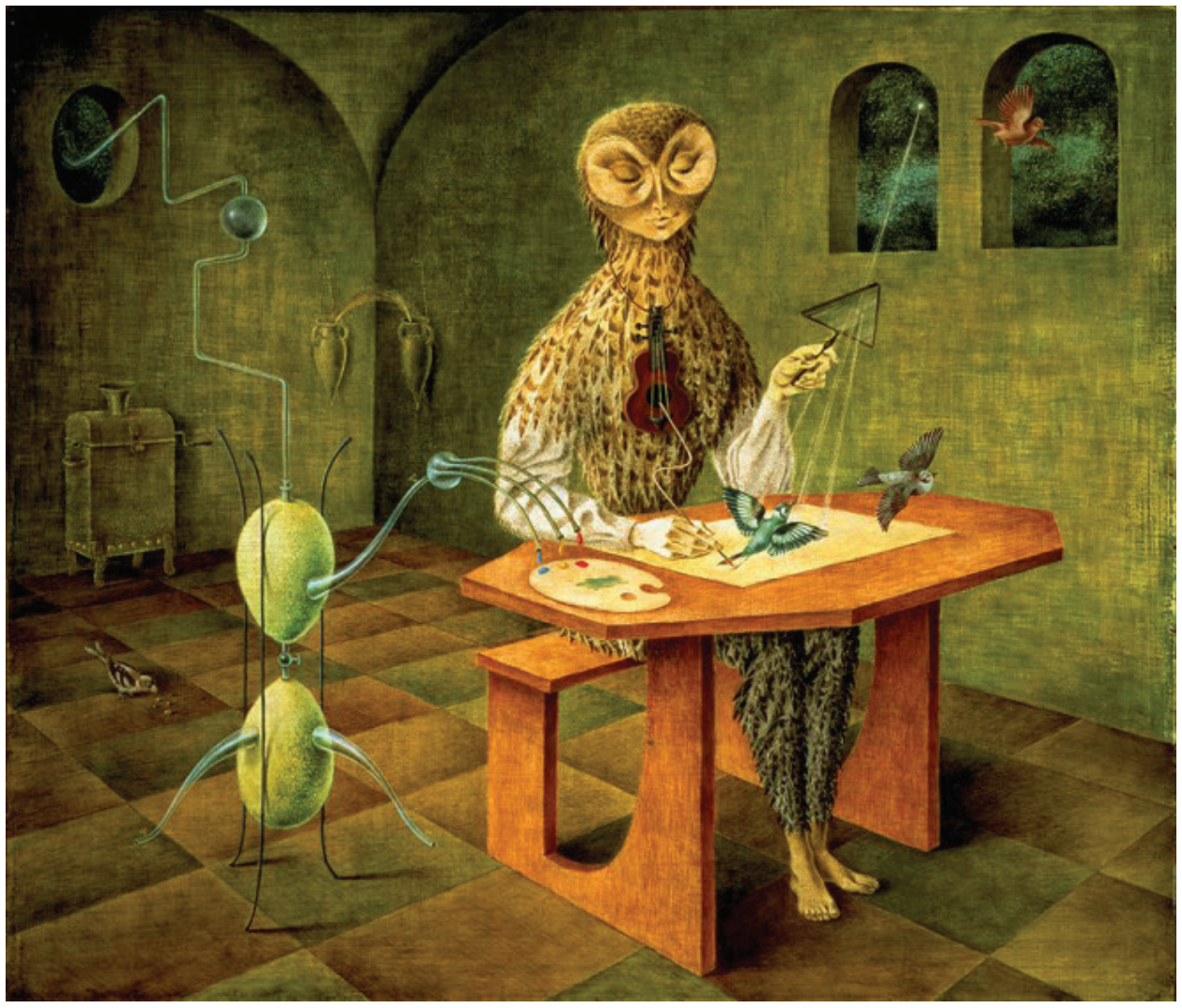

Fuente: Ovalle, Ricardo y Gruen, óleo sobre masonite "Remedios Varo: Catálogo razonado", 1998.

\section{Descripción y análisis formal de la obra}

Enmarcada en un contexto de estabilidad económica y emocional, así como cierto auge y aceptación por parte de la crítica artística de la época; Creación de las aves (figura 1) es considerada una de las obras maduras de Remedios Varo. Es notable la maestría que muestra en la representación de su personaje central, dentro de un ambiente místico, científico y artístico.

La pieza consta de una base de masonite sobre la cual el óleo logra gran adhesión. La artista eligió esta técnica para la gran mayoría de sus piezas. Brinda una textura delicada en el trazo de las figuras y detalles que destacan en su obra. La composición expone un minucioso estudio geométrico; es posible observarlo desde la base cuadriculada de la habitación, hasta los elaborados artefactos científicos, utilizados por el personaje central de la pieza. Denota la influencia de la 
formación recibida desde la infancia de Remedios, fortalecida años después por la rígida formación que le brindó la Academia de San Fernando.

En la obra se observa una estructura arquitectónica simple que remite a las antiguas construcciones del Cinquecento. Dicho aspecto es referido como una constante relación e influencia de pintura italiana del periodo renacentista, así como arte flamenco por medio de pinturas como las del Bosco. De estas obras es muy probable que Remedios Varo tomara como punto de referencia, para aplicar el uso de la perspectiva a sus propias pinturas, gracias a las constantes visitas al museo del Prado durante su infancia y formación académica.

Particularmente, Creación de las aves presenta una perspectiva lineal o cónica y deja al descubierto el interior de un espacio habitado por un ser creador. La disposición misma de cada elemento evidencia el gran manejo que la artista tenía de dicho estudio de perspectiva. A su vez, alude a la idea del cuadro como una ventana abierta al espectador, quien tiene la posibilidad de adentrarse con la mirada en un espacio pictórico definido por medio de la geometría.

Bajo esta lógica también fue elaborada gran parte de la producción pictórica durante el siglo XV y XVI en Italia, es decir, el periodo renacentista, en el cual los pintores reconocieron el valor del estudio de la perspectiva, tal como es el caso de León Battista Alberti, a través de su Tratado de pintura (Alberti, 1998).

De cierta manera, parte de los tópicos abordados en el tratado se ven reflejados al observar en la obra de Varo la aplicación de los fundamentos propuestos por Alberti. Por medio de su denominado velum ${ }^{4}$ sistematizó los principios del estudio de perspectiva, mismos que se reconocen en la composición cónica propuesta por Remedios al interior del estudio místico (figura 2).

\footnotetext{
3 Tablero de fibra de madera altamente comprimida.

4 Panel rectangular con traza reticular en el interior, diseñado por León Battista Alberti utilizado por él para identificar de forma visual la correcta proporción de los cuerpos en espacio definido, permitiendo generar con ello efectos de profundidad y volumen.
} 
Figura 2. Dibujo previo. Lápiz/ papel mantequilla 50 × 62

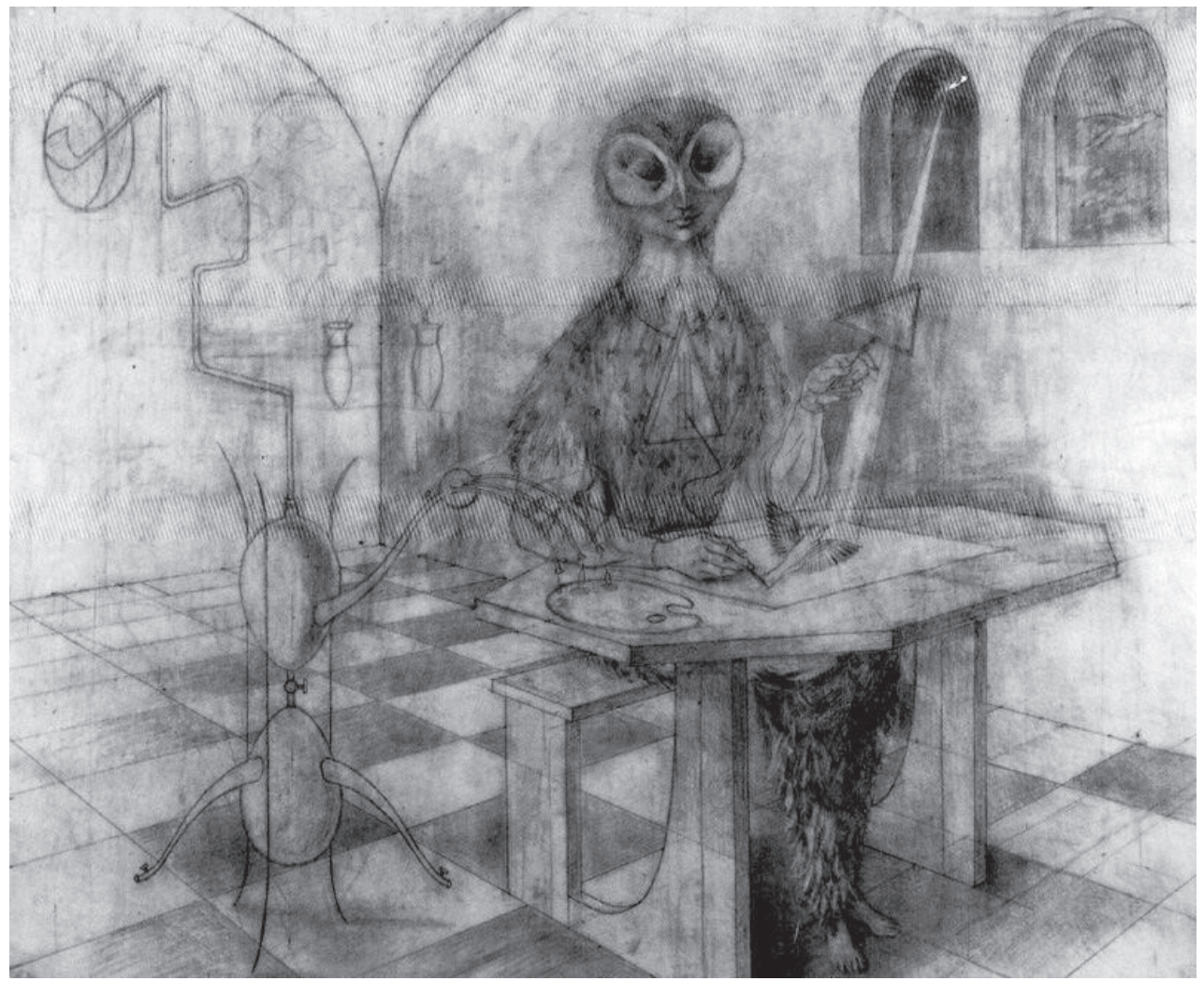

Fuente: Ovalle, Ricardo y Gruen, "Remedios Varo: Catálogo razonado", 1998.

En la pieza, las tres (3) ventanas del estudio permiten tener interacción con el exterior, por medio de la entrada de luz natural desde la derecha superior, dirigida en diagonal al interior de la habitación, en posición contraria a la luz artificial, que parte del lado inferior izquierdo, hacia el extremo derecho del estudio.

El uso de colores cálidos, así como el exhaustivo trabajo que muestra la artista en cada elemento, brinda a la pintura una textura de suavidad y un ambiente apacible, íntimo y adecuado para desempeñar la labor intelectual de la creación de seres animados.

En primera instancia, la atención se centra en la figura del personaje creador, particularmente en el instrumento que lleva colgado sobre su pecho, unido a un fino pincel que delinea la creación. 
En este punto, se retoma el estudio de Magnolia Rivera en relación con la producción visual de la artista española, expuesto en su texto Trampantojos: el círculo en la obra de Remedios Varo. El documento presenta el valor y significado que adquiere la circularidad como símbolo esencial en su obra, texto en el cual la autora sostiene que:

El círculo (en la obra de Remedios Varo) simboliza la unidad, la perfección, la totalidad, el absoluto, el destino, la eternidad, la protección y el vínculo. Representa al tiempo, a la palabra, al ojo que todo lo ve, a la matriz fecunda, a lo celestial. (Rivera, 2004, p. 13)

Esta idea se basa en la lógica de una geometría sacra, manifestada en las obras de la artista. Es bajo este principio que se resalta el trazo geométrico realizado sobre esta pieza por Magnolia Rivera, quien indica como eje central la figura del ser creador señalado dentro de una figura circular, de la cual irradian tres (3) líneas que atraviesan el punto central de la composición. A esta división se añade una separación por medio de cuatro (4) cuadrantes, proponiendo con ello una lectura radial en sentido de las manecillas del reloj, al tomar al instrumento musical como punto de partida para la descripción y análisis de cada uno de los objetos ubicados en la obra (figura 3).

Figura 3. División geométrica realizada originalmente por Magnolia Rivera, adaptada por Oscar González como propuesta para lectura de la obra

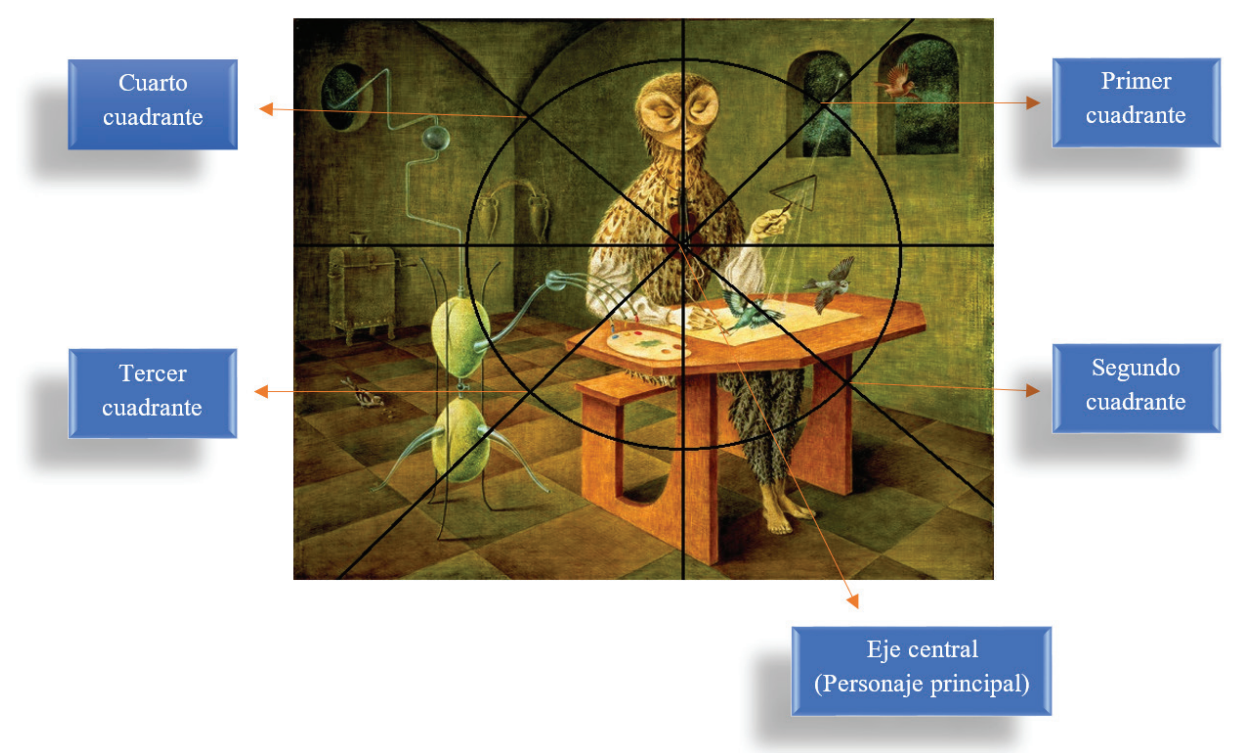

Fuente: Rivera, “Trampantojos. El círculo en la obra de Remedios Varo”, 2005. 
Ahora bien, es preciso fijar la mirada en la figura de un ser con rasgos delicados, ubicado en el eje central; posee una híbrida fisionomía al fusionar la cabeza y torso emplumado de una lechuza, complementado con brazos y piernas humanas. Dicho personaje lleva sobre su cuello un pequeño instrumento de tres (3) cuerdas, en donde una vez más se observa la fusión de elementos, al unir componentes de dos (2) instrumentos de cuerda, con algunos elementos de un violín y una guitarra.

En el primer cuadrante es posible observar la mano izquierda del personaje central. Sostiene una lupa con forma triangular que recibe la luz de forma diagonal proveniente de un astro celeste, visible por una de las ventanas. Sin dejar de lado el vuelo de un ave que se dirige al exterior en la ventana contigua. El segundo cuadrante mantiene relación directa con el eje central; está ligado por medio del instrumento musical, del cual emerge de la roseta un largo y curveado pincel; mismo con el que se delinean los rasgos de un ave a punto de elevar su vuelo, siguiendo la dirección de otra ave que recién comienza a elevarse, ambas diseñadas finamente por la mano derecha del personaje.

La labor realizada por el personaje central es Ilevada a cabo en un mesa-banco de madera con base octagonal, ubicado entre el segundo y tercer cuadrante, en el que se diseña y da vida a cada ave sobre un lienzo. La pigmentación que adquiere cada ave es otro elemento interesante; el color es obtenido por un inusual mecanismo que desde el exterior decanta las sustancias y pigmentos necesarios para llegar así a un par de matraces ovoides. Una vez concluido el proceso dentro de los mismos deposita los tres (3) colores primarios -azul, amarillo y rojo- dentro de un godete visible en el tercer cuadrante.

Por su parte, el cuarto cuadrante reafirma la simplicidad del estudio que brinda la sensación de profundidad al mostrarse un antiguo tostador de café al fondo de la habitación. Finalmente, en la esquina de la habitación se ubican dos (2) vasijas puntiagudas, colgadas en las paredes, que despiden y reciben fino polvo entre ellas, lo cual brinda al estudio cierto dinamismo; contrastado con la serenidad y concentración que deja ver la labor del personaje creador.

Hasta este punto, el enfoque lineal de construcción del pasado ha permitido definir y entender la descripción y análisis formal de la pieza. Pero ir más allá de esta somera descripción de valores visuales exige recurrir a otras herramientas metodológicas abordadas en el subsecuente análisis iconológico de la pintura. 


\section{Interpretación iconológica de la obra}

Posar la mirada sobre una obra artística implica por sí mismo un diálogo entre distintas temporalidades; un encuentro que reafirma la idea en la que "siempre ante la imagen, estamos ante el tiempo" (Didi-Huberman, 2008, p. 31). Con ello, se confrontan dos (2) formas de concebir la realidad: una imagen que expresa su propio mensaje desde el ayer y un espectador anclado a su propio tiempo, que acude a la imagen en busca de comprender el mensaje.

Este fenómeno es entendido por Walter Benjamin como dialéctica histórica en la cual "toda obra integra su pre-historia junto a su post-historia; y una post-historia en virtud de la cual su pre-historia se vuelve cognoscible en tanto implicada en un cambio constante" (Benjamin, 2009, p. 71). ¿Estas dos (2) temporalidades pueden llegar a un común acuerdo y generar con ello una idea del mensaje contenido en la imagen? La afirmación del cuestionamiento anterior da cabida y sentido a la labor de la historia del arte, disciplina que usa diversos métodos de aproximación al objeto artístico.

De esta forma, el análisis del presente artículo se orienta a través de la vía propuesta por Didi- Huberman, reconociendo la posibilidad que brinda aceptar el aporte del carácter anacrónico de toda aproximación al pasado. Partir de esta noción permitirá, desde el tiempo actual, comprender diversos valores que constituyen a la imagen a través de sus propios símbolos; así como tener una aproximación de la receptividad que tuvo la obra en su propio tiempo, contrapuesto al momento de la actualidad. En este sentido, el aporte principal del anacronismo para Huberman (2008) radica en "el modo temporal de expresar la exuberancia, la complejidad, la sobre determinación de las imágenes" (p. 39).

A partir de esta precisión se da comienzo al análisis iconológico por medio del reconocimiento de aquellos rasgos señalados como negativos por parte de la crítica artística de la época. Tal como señala Rodríguez Prampolini sobre el trabajo de Remedios Varo, existe un determinado alejamiento y falta de sensibilidad frente a la cosmovisión del país que le recibía (Prampolini, 1969).

Para entender a profundidad esta idea se centra la mirada en Creación de las aves para comenzar a entender algunos de los aspectos que influyeron en el pensamiento de la artista. El principal de ellos fue la lectura e interpretación de textos místicos y esotéricos, que atrajeron la atención de Remedios; dedicó gran parte de su tiempo para alcanzar un alto grado de entendimiento de nuevas formas de concebir la realidad, en los cuales se basa la representación gráfica de esta pieza. 
Uno de los principales autores, ante quien Varo mostró primordial interés, fue George Gurdjieff, maestro ruso, interesado en el misticismo y la búsqueda del conocimiento absoluto y verdadero, con gran influencia en los círculos de estudio de los artistas surrealistas. A principios del siglo XX, su escuela -Instituto para el Desarrollo Armónico del Hombre- tuvo gran aceptación entre diversas artistas e intelectuales en París. Allí accedían a un espacio de autoconocimiento y desarrollo humano; además, retomaba parte de las enseñanzas esotéricas y místicas hasta ese momento negadas a la mujer.

Es por tanto destacable el método empleado por Gurdjieff, basado en las artes-danza, música, así como la pintura- para desarrollar una conciencia en el hombre, aspecto en el que Tere Arcq (2008) señala que:

La práctica de labores manuales era de una importancia fundamental en la enseñanza de Gurdjieff. Ya desde el Priorato se dedicaba buena parte del tiempo al ejercicio de la costura, el tejido, el bordado y la pintura. ¿Por qué integró Gurdjieff estas prácticas a su enseñanza? Existen varias razones. Una de ellas es que el ejercicio de estas tareas permite dirigir la atención hacia un objeto durante largos periodos de tiempo, con lo que se controla el fluir de los pensamientos y se incrementa la concentración. Por otro lado, son actividades que contribuyen al desarrollo de la motricidad fina, que permite una evolución armónica del centro físico del ser humano. (p. 39)

Estos elementos vincularon diversas actividades realizadas por Remedios, aun cuando no tuvo oportunidad de participar de forma directa en la escuela dirigida por Gurdjieff. No obstante, fue a través de Christhoper Fremantle con quien tuvo un acercamiento al pensamiento gurdfiano a través de: "el estudio llamado Forma y color, ejercicios dedicados a la labor pictórica durante seis o siete horas, generalmente en completo silencio" (Fremantle, 1996, p. 12).

En este sentido, es sabido que Leonora Carrington, así como Kati Horna -fieles compañeras de Remedios Varo- compartían la misma afinidad por la práctica y comprensión del pensamiento de Gurdjieff. Dichas ideas fueron plasmadas en complejos textos como Relatos de Belcebú a su nieto, publicación la cual, mediante la exposición de leyes esotéricas basadas en la numerología y ciencias ocultas, explica principios y fundamentos del pensamiento humano, en relación con el significado y el propósito de la vida sobre la Tierra. 
En el texto de Gurdjieff es posible leer parte de la descripción de los elementos contenidos y adaptados en el cuadro de Remedios Varo, que alude al esbozo y desarrollo de la alquimia en oriente, mismos que servirán como referente para la descripción y relación simbólica de cada objeto realizada a continuación.

Por otra parte, es necesario tomar en cuenta el interés y defensa que muestra la pintora ante las antiguas enseñanzas, basadas en la alquimia y la escolástica ya que de acuerdo con Mircea Eliade (1974): "sólo hay un medio de comprender cualquier fenómeno cultural ajeno a nuestra coyuntura ideológica actual, (y este) consiste en descubrir el 'centro' e instalarse en él, para desde ahí alcanzar todos los valores que rige" (p. 13) y es justo el medio que Varo utilizó para plasmar su propia obra.

Esto es visible en Creación de las aves al encontrar elementos gráficos que remiten a las representaciones simbólicas de la escolástica, particularmente al cuadrivio, enseñanza medieval que dedicó su labor a la instrucción de geometría, aritmética, astronomía y música. Su objetivo principal es el alcanzar la inteligencia de las verdades reveladas (Abagnano, 2009), ciencias a las cuales la artista mostró constante interés.

De esta forma, en el cuadro no es ajeno encontrar la alusión a la sabiduría y creación, por medio de una figura con finos rasgos que, de acuerdo con el tamaño y forma de sus delicadas manos permiten inferir que la figura representada es la de una mujer, fusionada con un ave. Dicha idea se manifiesta "desde el antiguo Egipto, [donde se] simbolizan con gran frecuencia las almas humanas; a veces tienen cabeza de persona [...] símbolos del pensamiento, de la imaginación y de la rapidez de las relaciones con el espíritu" (Cirlot, 1998, p. 102)

Por su parte, la representación de la lechuza es otro elemento que remite a su presencia desde esculturas realizadas en la antigua Grecia; el ave es el emblema de Atenea, así como un ser nocturno en relación con la luna (Chevalier, 1999). Lo anterior muestra concordancia con la actividad llevada a cabo en la pintura, durante una apacible velada dentro de la habitación. Por tanto, en la imagen se evidencia la alegoría a la sabiduría de la mano con la naturaleza, a través de un ser que comprende el medio para dar vida a otros seres a través de su práctica -la pintura -, en contacto directo con la tierra, al mostrar los pies descalzos y con una notoria concentración en su labor. 
Entonces, los artefactos científicos y musicales que utiliza el sabio ser permiten la ejecución de su actividad, que parte de un instrumento que Gurdjieff define en su obra como:

Dzendvokh (el cual) consiste en un muy sólido marco de forma especial, hecho con colmillos de "mamuts", sobre el cual estaban extendidas muchas cuerdas de diversa longitud y espesor, hechas con "tripas de cabra" retorcidas y con el pelo de la cola de seres terrestres de diversas formas exteriores. (Gurdjieff, 2004)

Es posible que Remedios Varo reinterpretara dicho objeto al añadir elementos de un instrumento musical con tres (3) cuerdas, con características de un violín -por su voluta superior y delicadas clavijas- y una guitarra- de acuerdo con su curveada forma y roseta al centro-. La relación y práctica de la música, como elemento armónico, se encuentra latente en muchas de las civilizaciones antiguas que reconocen a los instrumentos de cuerda como aquellos vinculados con la armonía secreta del mundo.

Por tanto, serán variados los instrumentos que refieran a la evocación de la naturaleza. Como es el caso de la cítara: "en la edad media el sonido servía para evocar el canto de los pájaros hasta el extremo que, en el siglo XI se afirmaba que los pájaros eran verdaderos citaristas" (Berruezo, 1992, p. 22). Sin embargo, en la pieza de Remedios el personaje central no muestra un contacto directo con las cuerdas de este instrumento, sino por medio de un delicado pincel curvo que permite extraer las vibraciones sonoras, como la armonía secreta, y así dar forma, color y vida a su génesis.

Por otra parte, hace uso de un instrumento triangular cristalino, por el que atraviesa la luz de la luna, tomado con su mano izquierda. A este objeto Gurdjieff (2004), refiere como:

Una pequeña abertura en forma de hendidura con un "disco recolector", a través del cual pasaban los rayos de "luz" que entraban por la ventana y que se transformaban en un "rayo blanco concentrado" [...] que después de pasar por un cristal de forma especial, se dividía en siete "rayos coloreados" distintos, los cuales caían sobre una pequeña plancha de marfil llamada "Pirinjiel" [...] A través de este prisma, los seres instruidos contemporáneos del planeta Tierra, obtienen también del rayo blanco, siete rayos coloreados y también se imaginan que por medio de esto pueden llegar a saber algo acerca de otros fenómenos cósmicos. (p. 382) 
Arcq (2008) interpreta esta escena como "un astro que emite un rayo blanco, que pasa a través de un prisma y se descompone en tres rayos. Es el rayo de la creación que desciende desde el Absoluto, pasando por los planetas y los astros hasta llegar a la tierra" (p. 70). Por su parte, Mircea Eliade expone, en relación con el significado del triángulo como símbolo:

Fick y Eisler han interpretado el triángulo (delta) en el sentido de "vulva": Ia interpretación es válida a condición de conservar a este término su valor primario de matriz y fuente. Es sabido que la delta simbolizaba para los griegos a la mujer; los pitagóricos consideraban al triángulo como arché geneseoas a causa de su forma perfecta, pero también por que representaba su arquetipo de la fecundación universal. (Eliade, 1974, p. 41)

Otro elemento que resalta es la mesa octagonal sobre la cual se desarrolla la actividad creadora. Al respecto José Luis Alcubilla expone que:

El ocho es el número del equilibrio cósmico, de los cuadrantes de la rueda y de la rosa de los Vientos, que anuncia los puntos o direcciones cardinales a las que añaden las intermedias. El ocho y la figura llamada "octágono" median entre el cuadrado y el círculo, la tierra y el cielo. (Alcubilla, 2006, p. 10)

La anterior interpretación permite afirmar que más que un elemento estético o decorativo, la mesa octagonal se vuelve un símbolo armónico dentro de la exposición y discurso alquímico, que también era referido a la llamada piedra filosofal. De forma integral y continuando bajo esta lógica, la labor del ser creador no es llevada a cabo sin la pigmentación que caracteriza a cada una de las aves; colores extraídos por un aparato y mecanismo explicado posteriormente, del cual se obtienen los colores básicos en la gama cromática, que:

En la concepción analítica (según C.G. Jung) los colores expresan las principales funciones psíquicas del hombre: pensamiento, sentimiento, intuición y sensación.

El azul es el color del cielo, del espíritu: en el plano psíquico es el color del pensamiento.

El rojo es el color de la sangre, de la pasión, así como del sentimiento.

El amarillo es el color de la luz, del oro, de la intuición. [...] El verde es el color de la naturaleza, del crecimiento: desde el punto de vista psicológico, indica 
la función de sensación (función de lo real), la relación entre el soñador y la realidad. (Chevalier, 1999, p. 322)

Estos colores no sólo se ubican en el godete, también en los pájaros que emprenden el vuelo, después de haber sido finamente delineados. El objeto al que se hace alusión como herramienta científica, de acuerdo con Gurdjieff (2004), corresponde a una de las partes que conforman el instrumento Alla-atapan, el cual es:

Un soporte ordinario de tres patas en cuya parte superior estaban encajadas dos bolas, también de marfil, dispuestas una sobre la otra, siendo la bola superior mucho más grande que la inferior. En la bola inferior y más pequeña había una cavidad de forma especial situada exactamente frente a esa parte del Loosochepana por la cual habían pasado ya los rayos positivos coloreados. (p. 382)

Remedios Varo realiza una adaptación a estas esferas por medio de una forma ovoidal, lo cual les brinda un carácter mucho más significativo, referido ya desde:

El lenguaje jeroglífico egipcio como un signo determinante que simboliza lo potencial, el germen de la generación, el misterio de la vida. De esta forma la alquimia prosigue manteniendo este sentido, precisando que se trata del continente de la materia y del pensamiento. (Cirlot, 1998, p. 252)

Dicho instrumento mantiene cierta relación con los antiguos alambiques utilizados por los alquimistas, mediante los cuales se realizaban una serie de procedimientos con elementos químicos, con la finalidad de transformar su esencia original y crear oro. Sin embargo, la pintora deja de lado la ostentosa pretensión de transformar materia química a elementos con alto valor, para únicamente extraer del manto estelar el también reconocido por la alquimia como polvo de estrella, transformado en pigmento especial.

En relación con el objeto ubicado en el extremo izquierdo central de la habitación resulta interesante la interpretación de Rafael Santos Toroella quien define a este objeto como "sencillamente, una tostadora de café, que hace notar el humor de Varo, al mezclar lo cotidiano y lo trascendente" (Varo, 1997, p. 51). La alusión a lo cotidiano será una constante en otras de sus obras, evidente en la pieza Papilla estelar, pintura en la cual utiliza un molino de semillas para triturar 
las estrellas que alimentan al astro lunar. Es bajo esta idea que resulta posible que dicho tostador de café mantenga vínculo con la misma acción de triturar cuerpos celestes.

Ahora bien, la interrelación de sustancias y la magia dentro del estudio se hacen latentes en el intercambio de finas sustancias; comparten entre sí su contenido al hacer pasar de una vasija a otra lo que pareciera ser una especie de fino polvo.

Esta representación remite a uno de los arcanos del tarot, la Templanza: el agua entre las dos vasijas simboliza la fusión entre lo material y lo espiritual, el equilibrio. Además de este referente esotérico, es también una imagen literal de Los vasos comunicantes de Breton, que ponen en relación el mundo real y el del sueño, el consciente y el inconsciente, la visión interior y la realidad exterior. Pero "vasos comunicantes" es también el nombre del experimento científico que demuestra qué gases o líquidos vertidos en dos recipientes comunicados mantienen el mismo nivel en ambos, sea cual sea su forma. Varo utiliza una potente imagen visual en la que confluyen referencias a la ciencia, los saberes mágicos y el surrealismo. (Madrid, 2013, p. 430)

Como es notable, son diversas las alusiones y tradiciones que se ubican en una sola imagen; lleva a cabo un proceso de interpretación, así como relaciones anacrónicas que en conjunto permiten una mayor proximidad hacia aquello que busca expresar la pintura por sí misma. Hacer uso de diversas relaciones e interpretaciones de signos en una imagen evidencia el acto de montaje y desmontaje al estudiar una obra.

Bajo esta idea, el montaje es entendido como "un modo de desplegar visualmente las discontinuidades del tiempo presente en toda secuencia de la historia" (Didi-Huberman, 2009, p. 430) para ofrecer una noción de memoria e idea de desciframiento del mensaje contenido por la imagen. Por tanto, el acto mismo de acercarnos a comprender la obra Creación de las aves implica en sí un acto de continuo montaje para reformular el entendimiento de una pieza; construida en el pasado, resignificada en el ahora. 


\section{Comentarios finales}

El encuentro con una obra artística provoca, en quien decide dialogar con la pieza, una serie de desciframientos y lecturas que indudablemente confrontan al pasado frente al presente. Al reconocer este acto, la labor de interpretación de una pintura como Creación de las aves lleva a estructurar determinada noción del significado de la pieza.

De esta manera, por medio de un encuentro dialéctico con la obra de arte se logra dar sentido de forma temporal a la significación de una imagen. En palabras de Didi-Huberman (2004): "la dialéctica debe comprenderse en el sentido de una colisión desmultiplicada de palabras e imágenes: las imágenes chocan entre sí para que surjan las palabras, entran en colisión para que visualmente tenga lugar el pensamiento" (p. 205).

A partir de este proceso es posible definir el estado de recepción y significado que ha tenido Creación de las aves a lo largo de su propia vida. Asimismo, en el tiempo presente la pintura ha dejado de ser juzgada ante la distancia mostrada por sus imágenes, frente a alegorías identitarias del contexto mexicano, como señalaba contemporáneamente Prampolini al observar la pintura.

Hoy en día Creación de las aves es expuesta en las salas del Museo de Arte Moderno como una pieza que expresa la manifestación artística del surrealismo en México. Es considerada una obra de gran importancia dentro de la colección Isabel Gruen Varsoviano e historia del arte mexicano. Ambas instituciones - museo y colección- dotan a la obra de gran valor y sentido, enriqueciendo su propia historia y post-historia, como refiere Walter Benjamin.

Entonces, el presente ejercicio de análisis visual es un acto de montaje no sólo de símbolos e imágenes, sino también de interpretaciones y significados en esta pintura, lo cual aporta una interpretación de las múltiples lecturas que pudiese tener la misma obra. De esta manera, se concluye el presente análisis no sin antes convocar a que, quien así lo decida, lleve a cabo el desmontaje de nueva cuenta a la creación de Remedios Varo y cuestione a la pintura desde otras tantas posibles realidades y significaciones, ofreciendo diversas alternativas de re-montaje de esta obra visual. 


\section{8}

\section{Referencias}

Abagnano, A. V. (2009). Historia de la Pedagogía. México: FCE.

Aguado, R. M. (2018). Arte en la academia. Pintores en la Real Academia de Bellas (Siglo XX) (Tesis doctoral). Madrid: Universidad Complutense de Madrid.

Alberti, L. B. (1998). Tratado de pintura. México: UAM.

Alcubilla, J. L. (2006). Creación de las aves. Cuadro de Remedios Varo. México: FCE.

Arcq, T. (2008). En busca de lo milagroso. En Cinco Llaves del mundo secreto de Remedios Varo (p. 23). México: Artes de México.

Benjamin, W. (2009). Obras II. Madrid: Abada.

Berruezo, J. (1992). El mundo de lo oculto (Vol. 6). Barcelona: Marin SA.

Bogzaran, F. (2008). Sueños de Alquimia. En Cinco Llaves del mundo secreto de Remedios Varo (p. 163). México: Artes de México.

Bretón, A. (1924). Manifiesto surrealista. Buenos Aires: Argonauta.

Chevalier, J. (1999). Diccionario de los símbolos. España: Herder.

Cirlot, J. E. (1998). Diccionario de símbolos. España: Siruela.

Didi-Huberman, G. (2004). Imágenes pese a todo. Barcelona: Paidos.

Didi-Huberman, G. (2008). Ante el tiempo. Historia del tiempo y anacronismo de las imágenes. Buenos Aires: Adriana Hidalgo.

Didi-Huberman, G. (2009). Historia del arte y tiempo de los fantasmas según Aby Warburg. Madrid: Abada. 
Eliade, M. (1974). Herreros y Alquimistas. Madrid: Taurus.

Fremantle, C. (1996). De la atención. Caracas: Ganesha.

Gurdjieff, G. (2004). Relatos de Belcebú a su nieto. Malaga: Sirio.

Kaplan, J. A. (2001). Viajes Inesperados. El arte y vida de Remedios Varo. D.F: Era.

Madrid, M. J. (2013). Surrealismo y saberes mágicos en la obra de Remedios Varo (Tesis doctoral). Barcelona: Universidad de Barcelona.

Prampolini, I. R. (1969). El surrelismo y el arte fantástico en México. México: UNAM.

Rivera, M. (2004). Trampantojos. El círculo en la obra de Remedios Varo. México: Siglo XXI.

Tibol, R. (8 de Julio de 1957). Artes Plásticas: primera investigación de Remedios Varo. Novedades, 6.

Varo, R. (1997). Cartas, sueños y otros textos. México: Era. 